\title{
Late Health Effects of Childhood Nasopharyngeal Radium Irradiation: Nonmelanoma Skin Cancers, Benign Tumors, and Hormonal Disorders
}

\author{
CÉCILE M. RONCKERS, CHARLES E. LAND, RICHARD B. HAYES, PIETER G. VERDUIJN, \\ MARILYN STOVALL, AND FLORA E. VAN LEEUWEN
}

\begin{abstract}
Department of Ear, Nose and Throat Medicine, Reinaert Kliniek, Maastricht, The Netherlands [C.M.R., P.G.V.]; Division of Cancer Epidemiology and Genetics, National Cancer Institute, Bethesda, Maryland, U.S.A. [C.M.R., C.E.L., R.B.H.]; Department of Radiation Physics, The University of Texas M. D. Anderson Cancer Center, Houston, Texas, U.S.A. [M.S.]; Department of Epidemiology, The Netherlands Cancer Institute, Amsterdam, The Netherlands [F.E.v.L.]
\end{abstract}

\begin{abstract}
Nasopharyngeal radium irradiation (NRI) was widely used from 1940 through 1970 to treat otitis serosa in children and barotrauma in airmen and submariners. We assessed whether NRI-exposed individuals were at higher risk for benign tumors, nonmelanoma skin cancer, thyroid disorders, and conditions related to regulatory control of anterior pituitary hormones, such as growth and reproductive characteristics. We conducted a retrospective cohort study in 3440 NRI-exposed and 3088 nonexposed subjects, who as children were treated at nine ear, nose and throat clinics in The Netherlands between 1945 and 1981. Based on information from original medical records, we traced vital status through follow-up at municipal population registries. Disease status (including medical confirmation) and indicators of pituitary gland radiation damage were assessed from a selfadministered questionnaire in 1997 . The average radiation doses were 11,7 , and 1.5 cGy for pituitary, parotid, and thyroid gland, respectively, and $3.2 \mathrm{cGy}$ for the facial skin. Among exposed subjects, 23 benign head and neck tumors were observed, compared with 21 among nonexposed subjects. Elevated risk of basal
\end{abstract}

\section{ABSTRACT}

cell carcinoma of the head and neck area was observed in exposed subjects (odds ratio $=2.6 ; 95 \%$ confidence interval: 1.0-6.7). Exposed and nonexposed groups did not differ substantially with regard to thyroid disorders, height, and reproductive characteristics, although exposed males more frequently reported a history of fertility problems compared with nonexposed males (odds ratio $=1.4 ; 95 \%$ confidence interval: 1.0 2.1). We found no evidence of highly elevated risk of benign head and neck tumors, nonmelanoma skin cancer, thyroid disorders, or indicators of pituitary radiation damage after childhood NRI in The Netherlands. (Pediatr Res 52: 850-858, 2002)
BCC, basal cell carcinoma
SCC, squamous cell carcinoma
NMSC, nonmelanoma skin cancer
NRI, nasopharyngeal radium irradiation
OR, odds ratio
CI, confidence interval

From the early 1940s until 1960, NRI was regarded as a safe and effective treatment for (childhood) otitis serosa (1-4) and barotrauma (aerotitis media) in military submariners and airmen $(5,6)$. These conditions are characterized by lymphoid hyperplasia in the nasopharynx, causing impaired eustachian tube functioning, hearing loss, and pain. In the late 1920s, Dr. S.J. Crowe developed a small radium applicator attached to a pin that could be inserted through the nostrils into the naso-

Received September 24, 2001; accepted February 18, 2002.

Correspondence: Cécile M. Ronckers, Ph.D., Radiation Epidemiology Branch, Division of Cancer Epidemiology and Genetics, National Cancer Institute, 6120 Executive Boulevard, Bethesda, MD 20852-7238, U.S.A.; e-mail: ronckerc@mail.nih.gov

Supported by the National Cancer Institute, grant N01CP33013, and partially by interagency agreement Y3CP0012-01 between the Centers for Disease Control and the National Cancer Institute.

DOI: 10.1203/01.PDR.0000034232.09928.77 pharynx, where the radium exerted its activity on the "overflow of lymphoid tissue" $(1,2)$. NRI was used in several European countries, the United States, and Canada $(7,8)$. The Centers for Disease Control and Prevention has estimated that between 0.5 and 2 million children were treated in the United States, as well as 8000 military submariners and aviators (7).

After childhood radiation exposure, elevated risks of benign head and neck tumors and NMSC have been reported (9-12), as well as benign radiation-related disorders of the thyroid, e.g. nodular disease and hypothyroidism $(13,14)$. However, compared with NRI-exposed subjects, radiation doses to relevant organs were higher in the latter studies. In NRI, the pituitary gland receives relatively high doses of $\gamma$-radiation (range, 0.01-0.59 Gy) compared with other head and neck organs (15) because of its close proximity to the treatment areas in the 
nasopharynx (16). If NRI results in damage to the pituitary gland, this might affect circulating hormone levels $(17,18)$, growth, and reproductive characteristics, e.g. early menarche, fertility problems, and early menopause, as has been observed among cancer patients who were treated with high-dose (20-70 Gy) cranial radiotherapy at childhood ages (19-21). So far, only scarce data are available on the occurrence of disorders other than cancer among NRI-exposed populations $(8,22)$.

In The Netherlands, NRI was introduced after WW II and was used widely until the early 1970 s (8). We retrospectively traced original radiation treatment records of 5358 patients. In previous reports, we described mortality (15) and cancer incidence (23) in this population. The present report describes nonmelanoma skin cancers and nonmalignant disorders possibly associated with NRI exposure.

\section{METHODS}

Study population and data-collection. Building on a previous study (24), we defined an expanded cohort of 5358 NRIexposed and 5265 nonexposed subjects. Nonexposed subjects were frequency-matched to the exposed group by clinic, sex, birth year, and first consultation year; they had also been treated for ear, nose, and throat (ENT) conditions, but had never been exposed to NRI. From the individual ENT treatment charts in the nine participating clinics, we recorded history of NRI (yes/no), a code for diagnosis at first consultation, and, for exposed subjects, individual treatment characteristics, including date and duration of each treatment session. Institutional review boards of all participating hospitals and research institutes approved the study protocol. Detailed descriptions of the definition of the cohort, data collection, follow-up, and dosimetric methods have been reported elsewhere $(15,23)$.

Radiation dosimetry. NRI treatment protocols varied by clinic, with the treatment prescription ranging from 3 to 74 mgh (mgh: milligrams radium $\times$ treatment duration in hours). Organ-specific doses were calculated based on simulations in age-appropriate, anthropometric phantoms, taking into account the distance from the radium applicator to the organ of interest $(15,16)$. Mean absorbed tissue doses (range) were as follows: nasopharynx: 275 cGy (32-1110), pituitary gland: 11 cGy (1-59), parotid gland: 7 cGy (1-28), thyroid gland: 1.5 cGy (0.2-11), and facial skin: 3.2 cGy (0.5-13).

Follow-up. Cohort members were traced through a search at municipal resident registries to determine vital status and address (if applicable) on September 15, 1997. For all subjects who remained untraceable, additional searches were done at the registry of emigrants and immigrants of the Dutch Ministry of Foreign Affairs and at the Central Bureau of Genealogy, a nationwide registry of deceased Dutch citizens.

Health status assessment. We conducted a survey to assess health status, including cancer and noncancer outcomes. A questionnaire accompanied by a letter of introduction from an ENT physician of the hospital where the subject was treated and an informed consent form were mailed to all living subjects, as of 1997, in the cohort. Exposed and nonexposed subjects received identical letters, in which the purpose of the study was described as an evaluation of long-term health effects of several ENT treatments, including NRI. The study included a telephone survey of subjects who did not respond after two written requests. The questionnaire contained 43 items covering sociodemographic items, diseases known to be related to high-dose radiation to the head and neck area, and possible confounders (occupation, smoking, alcohol consumption, and exposure to various radiation sources).

The items on noncancer outcomes were stated as follows: "Did you ever have any of the following conditions or diseases?" with check boxes for "yes," "no," and "don't know." The outcomes of interest included thyroid disease, growth disorder, and fertility problems. A multiple-choice item assessed the diagnosed cause of fertility problems (sperm disorder in males, obstruction of fallopian tubes in females, hormonal disorders, other cause, unknown, or "prefer not to answer this question"). As we were interested in fertility problems and diagnosis of the participant only, and not in any such diagnoses of the participants' spouses, the questions were tailored to the participant's situation rather than a couple's fertility history and the multiple-choice item was asked for men and women separately, to allow for a cross-check with the participant's gender.

Among females, we also assessed age at menarche $(<12$, $12-14,>14$ y), number of miscarriages and age at last menstrual period. If the self-reported last menstrual period had taken place more than $1 \mathrm{y}$ before questionnaire completion and there was no mention of pregnancy or breast-feeding at the time of questionnaire completion, the woman was considered to be postmenopausal. If the general remark section or the response concerning hospital admissions indicated a hysterectomy and/or oophorectomy, we considered the woman to have had a "surgical menopause"; otherwise, postmenopausal women were classified as having had "natural menopause."

In addition, four items (on tumors, biopsies, hospital admissions, and radiation therapy) were used to identify subjects who had ever suffered from a malignant or benign tumor, specified by organ or tissue. In an additional letter, subjects reporting a tumor were asked for the name of the treating physician and to complete a second consent form to allow release of medical data for study purposes. After consent was obtained, physicians were asked for copies of relevant correspondence or medical chart notes regarding the tumor or the underlying disease necessitating hospital admission, biopsy, or radiation treatment. As the main focus was on disorders of the head and neck area, we did not seek medical confirmation for skin lesions known to be located below the diaphragm or on the extremities. We applied a similar medical verification procedure for all subjects who reported a history of thyroid disease.

Definition of analytic cohort. From the total cohort of 10,623 subjects, $92 \%$ were traced, of whom 617 had died and 9142 were alive, with known addresses. In all, 3440 (74\%) exposed and $3088(68 \%)$ nonexposed subjects participated in the survey and were thus eligible for the present analyses (Table 1). Analyses of adult height and reproductive characteristics were restricted to subjects who were $<10$ y of age at time of ENT treatment ( $n=4944,76 \%$ of all participants), and would therefore be assumed not to have entered the pubertal growth spurt or, for female subjects, experienced menarche. 
Table 1. Follow-up status in The Netherlands NRI cohort study

\begin{tabular}{lcc}
\hline $\begin{array}{c}\text { Follow-up status } \\
\text { (as of September 15, 1997) }\end{array}$ & $\begin{array}{c}\text { Exposed } \\
{[\text { No. (\%)] }}\end{array}$ & $\begin{array}{c}\text { Nonexposed } \\
{[\text { No. (\%)] }}\end{array}$ \\
\hline Alive & $4624(86)$ & $4518(86)$ \\
Participation & $3440(74)^{*}$ & $3088(68)^{*}$ \\
Refusal & $586(13)^{*}$ & $728(16)^{*}$ \\
Nonresponse & $598(13)^{*}$ & $702(16)^{*}$ \\
Deceased & $302(6)$ & $315(6)$ \\
Emigrated & $265(5)$ & $259(5)$ \\
Lost to follow-up & $167(3)$ & $173(3)$ \\
Overall & 5358 & 5265 \\
\hline
\end{tabular}

* Percentage of total number of subjects eligible for the questionnaire survey (i.e. alive).

Data analysis. The questions on ever having suffered from ENT disorders, epilepsy, hormonal, growth, and thyroid disorders were grouped together in one section of the questionnaire. Descriptive analyses revealed that a considerable proportion of subjects had reported a history of one or two conditions, but had not completed the checkboxes for all other questions in this group. As a result, we observed up to $20 \%$ of missing observations for some of these disorders. As the proportions of missing observations per disorder were very similar for exposed and nonexposed groups, we interpreted missing observations for these 10 questions to be a "no" if one or more of the other questions in this section was answered affirmatively. Subjects with missing responses for all 10 questions [58 exposed (1.7\%), and 72 nonexposed $(2.3 \%)]$ were excluded from analyses involving these 10 questions. Only disorders occurring after ENT treatment were taken into account in the analyses.

Frequency tables of disorders of interest were assembled for exposed and nonexposed groups and homogeneity was tested using Pearson $\chi^{2}$ tests (25). Logistic regression models (26) were used to obtain OR and $95 \%$ CI adjusted for gender, attained age, and other possible confounders, as appropriate. Because the disorders and characteristics under study often show nonlinear associations with age, we modeled age at time of questionnaire survey as a categorical variable $(<30,30-39$,
$40-49,50-59,60-69$, and $\geq 70$ y), or $(<40,40-49,50-59$, and $\geq 60 \mathrm{y}$ ) when sparse numbers of cases did not allow for finer stratification. Likelihood ratio tests for trend in radiation dose were performed by adding dose to the model as a single continuous variable. As adult height was normally distributed in our cohort, we used the $t$ test to compare the average adult height between the exposed and nonexposed groups.

\section{RESULTS}

The NRI-exposed and nonexposed subjects were comparable with regard to attained age (Table 2). The proportion of subjects treated before age $5 \mathrm{y}$ was greater among nonexposed compared with exposed subjects, because we matched the nonexposed group on calendar year of first consultation in the exposed group, rather than calendar year of first radiation treatment. Among exposed subjects, the median age at treatment was $6.5 \mathrm{y}$ and the median attained age was $40.9 \mathrm{y}$.

Table 3 shows the frequency of medically confirmed benign tumors in the head and neck area. Among exposed subjects, 23 benign head and neck tumors (excluding skin tumors) were observed, compared with 21 among nonexposed subjects. The number of tumors for each site of interest in the head and neck was small and equally distributed over exposed and nonexposed groups: in all, five benign salivary gland tumors, eight thyroid gland tumors, and two pituitary adenomas were observed. No benign brain tumors were observed in the entire cohort (23).

The data presented on skin tumors focus on medically confirmed cases. A total number of 615 subjects reported a history of potential skin tumors. Medical confirmation was not sought for $40 \%$ of all self-reported potential skin tumors, as these lesions were clearly benign, or concerned skin lesions of lower body parts. Among all subjects whom we asked for permission to medically verify the reported skin lesion, $84 \%$ of exposed and $77 \%$ of nonexposed subjects gave consent. The physician cooperation proportion was high, i.e. $>95 \%$ in both exposure groups. Out of all self-reported cases for which

Table 2. Population characteristics of The Netherlands NRI cohort by exposure status

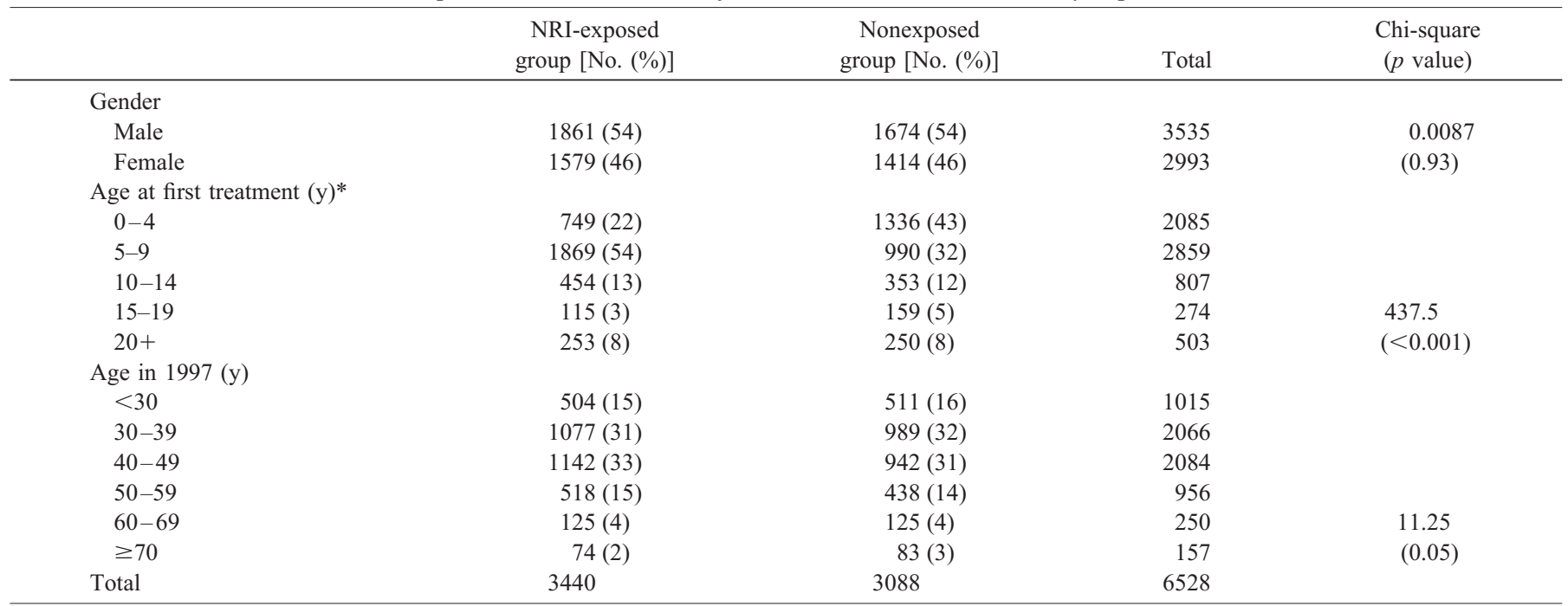

* Date of first treatment refers to first radium treatment session among exposed and to first consultation among nonexposed subjects. 
physician cooperation was obtained, medical information was available in $80 \%$ of cases, and within that group, more than $70 \%$ were benign skin tumors or nonneoplastic skin disorders (approximately similar for exposed and nonexposed subjects).

The frequency of benign skin tumors of all body parts was very similar for exposed and nonexposed subjects (Table 3). Among exposed subjects, only two SCC of the skin, both of the lower lip, were observed, compared with one SCC of lower body parts in nonexposed subjects. The total number of BCC was slightly higher among exposed subjects $(\mathrm{OR}=1.3)$, but the proportion of BCC located in the head and neck area was higher among exposed than among nonexposed subjects [ $84 \%$ versus $43 \%$, respectively, $\left.p\left(\chi^{2}\right)=0.06\right]$. The risk of BCC restricted to the head and neck area was borderline significantly elevated $(\mathrm{OR}=2.6,95 \% \mathrm{CI}: 1.0-6.7)$. For other body parts, no excess was found $(\mathrm{OR}=0.3,95 \% \mathrm{CI}$ : $0.1-1.3)$. Among exposed subjects, we then compared the subgroup exposed to higher than median facial skin doses ( $>2$ cGy, 1187 subjects, 12 cases of head and neck BCC) with the group with median or lower skin doses ( $\leq 2 \mathrm{cGy}, 2253$ subjects, four cases) and found a slightly (statistically nonsignificant) elevated risk of head and neck BCC (OR $=1.8,95 \%$ CI: 0.6-6.8).

With regard to nontumor disease outcomes, we first assessed the reported frequency of thyroid disorders among exposed and nonexposed subjects (Table 4). Originally, 105 exposed and 81 nonexposed subjects reported a history of thyroid disease in the questionnaire. Consent for medical verification was obtained for $58 \%$ and $62 \%$ of exposed and nonexposed subjects, respectively.

Forty-three benign thyroid disorders were confirmed among exposed subjects compared with 40 among nonexposed subjects $(\mathrm{OR}=1.0)$. Overall, there was no difference in the cumulative incidence of hypothyroidism. Among females, a history of nodular thyroid disease was more common among exposed subjects compared with nonexposed subjects $(1.2 \%$ versus $0.8 \%$ ) but the difference was not statistically significant. The age- and sex-adjusted OR for nodular disease among exposed subjects was 1.4 (95\% CI: 0.7-2.7). Additional adjustment for age at treatment did not affect the risk estimates for thyroid disease or nodular disease and there was no heterogeneity of risk over subgroups according to thyroid dose (not shown).

We assessed self-reported adult height (Table 5) and reproductive characteristics (Table 6) as indicators of possible radiation-related pituitary gland dysfunction among subjects younger than $10 \mathrm{y}$ of age at time of treatment. Table 5 shows that height was almost identical when gender and age-specific exposed and nonexposed groups were compared. In the entire cohort, a clear trend of height with birth cohort was apparent.

The right column of Table 5 shows age-specific self-reported height from a 1997 nation-wide population survey conducted by Statistics Netherlands among 22,344 Dutch citizens (27). The trend related to birth cohort was similar and reported height was, on average, comparable, although both exposed and nonexposed males who were younger than $30 \mathrm{y}$ of age in 1997 were slightly less tall than the reference population.

Exposed subjects and nonexposed subjects were equally likely to be shorter than the third percentile of adult stature in the Netherlands $[1.57 \mathrm{~m}$ for females and $1.69 \mathrm{~m}$ for males (19)], after adjustment for age at treatment, attained age, and sex. Subjects exposed to the highest radiation doses to the pituitary gland ( $\geq 20 \mathrm{cGy}$ ) were even less likely than lessexposed subjects $(1-19 \mathrm{cGy})$ to be shorter than the sex-specific third percentile.

Table 3. Medically confirmed benign tumors and nonmelanoma skin cancers among participants of The Netherlands NRI cohort study survey, by exposure status

\begin{tabular}{|c|c|c|c|c|}
\hline \multirow[b]{2}{*}{ Condition } & \multirow[b]{2}{*}{ ICD-9* } & \multicolumn{2}{|c|}{ Number of cases } & \multirow[b]{2}{*}{$\begin{array}{c}\text { OR } \\
(95 \% \mathrm{CI}) \dagger\end{array}$} \\
\hline & & $\begin{array}{c}\text { Exposed } \\
(n=3440)\end{array}$ & $\begin{array}{l}\text { Nonexposed } \\
(n=3088)\end{array}$ & \\
\hline Benign head and neck tumors & $210,(212-215) .0-1,224,226,227.0-3$ & 23 & 21 & $1.0(0.5-1.7)$ \\
\hline Salivary glands & 210.2 & 2 & 3 & \\
\hline Pituitary adenoma & 227.3 & 1 & 1 & \\
\hline Thyroid gland & 226 & 4 & 4 & \\
\hline Parathyroid gland & 227.1 & 1 & 0 & \\
\hline Benign skin tumors: & 216 & 58 & 45 & $1.2(0.8-1.7)$ \\
\hline Head and neck area & $216.0-4$ & 24 & 19 & $1.1(0.6-2.1)$ \\
\hline Other & $216.5-9$ & 34 & 26 & $1.2(0.7-1.9)$ \\
\hline SCC of the skin & 173 & 2 & 1 & \\
\hline Head and neck area & $173.0-4$ & 2 & 0 & \\
\hline Other & $173.5-9$ & 0 & 1 & \\
\hline $\mathrm{BCC}$ of the skint\# & 173 & 19 & 14 & $1.3(0.6-2.6)$ \\
\hline Head and neck area & $173.0-4$ & 16 & 6 & $2.6(1.0-6.7)$ \\
\hline Other & $173.5-9$ & 3 & 8 & $0.3(0.1-1.3)$ \\
\hline
\end{tabular}

* International Classification of Diseases, $9^{\text {th }}$ Revision (Ref. 28).

$\uparrow$ Adjusted for attained age $(<40,40-49,50-59,60+y)$ and gender; OR only estimated when at least 10 cases were observed in the cohort.

†nly first skin tumors were included in analysis.

T Numbers of exposed/nonexposed head and neck tumors, for sites not listed separately in the table, are as follows: lip, mouth, and pharynx other than major salivary glands (ICD-9: 210.x except 210.2), 4/5; bones of skull/face (213.0), 1/0; eye (224), 1/0; lipoma (214.0-1), 9/8; no benign brain tumors were observed in the entire cohort;

\# Of 33 subjects with at least one BCC, 27 had one lesion, three subjects had two BCC, one subject had three BCC, and one subject had four BCC, not restricted to the head and neck area. In addition, one (exposed) subject had recurrent and multiple primary BCC and SCC lesions of the nose, jaw, cheek, and parotid gland. In all, of six subjects with multiple lesions, two were exposed to NR. 
Table 4. Thyroid disorders among participants of The Netherlands NRI cohort study survey, by exposure status and gender

\begin{tabular}{|c|c|c|c|c|c|c|c|c|c|}
\hline & \multicolumn{4}{|c|}{ Females only } & \multicolumn{4}{|c|}{ Overall* } & $\begin{array}{c}\text { OR } \\
(95 \% \mathrm{CI}) \ddagger\end{array}$ \\
\hline Self-reported thyroid disorder $\dagger$ & 75 & 4.7 & 62 & 4.4 & 105 & 3.1 & 81 & 2.6 & $1.2(0.9-1.6)$ \\
\hline \multicolumn{10}{|l|}{ Medical verification possible? } \\
\hline Consent obtained & 47 & & 41 & & 61 & & 50 & & \\
\hline Benign thyroid disease\$ & 34 & 2.2 & 33 & 2.3 & 43 & 1.3 & 40 & 1.3 & $1.0(0.6-1.5)$ \\
\hline Nodular disease & 19 & 1.2 & 11 & 0.8 & 20 & 0.6 & 13 & 0.4 & $1.4(0.7-2.7)$ \\
\hline Thyrotoxicosis & 6 & 0.4 & 7 & 0.5 & 11 & 0.3 & 10 & 0.3 & $1.0(0.4-1.8)$ \\
\hline Graves disease & 2 & 0.1 & 4 & 0.3 & 5 & 0.2 & 5 & 0.2 & $0.9(0.3-3.0)$ \\
\hline Hypothyroidism & 4 & 0.3 & 6 & 0.4 & 5 & 0.2 & 6 & 0.2 & $0.8(0.2-2.5)$ \\
\hline Other thyroid disorders\# & 3 & 0.2 & 1 & 0.1 & 4 & 0.1 & 1 & 0.03 & \\
\hline
\end{tabular}

* All $p$ values of the crude $\chi^{2}$ test for exposure effect among males and females separately were $>0.2 ; p$ values only calculated if the expected frequency of all cells was $>5$.

$\dagger$ Number of missing observations for this item: exposed group (58), nonexposed group (72).

$\$$ Adjusted for attained age $(<40,40-49,50-59,60+$ y) and gender only; only estimated when at least 10 cases were observed in the cohort.

I Among the total of $97(52+45)$ self-reported cases in which the physician intended to cooperate, there were six cases (four exposed, two nonexposed) in which the medical file was incomplete and did not contain data on thyroid disorders.

\$ Includes International Classification of Diseases, 9th revision (Ref. 28) codes 226 and 240-246.

\# Four thyroid cancers and one benign parathyroid tumor; risk estimates for malignant disorders (including cases ascertained from a cancer registry linkage procedure) have been reported elsewhere (Ref. 23).

Table 5. Adult height among participants of The Netherlands NRI cohort study survey who were treated before age $10 y$, by gender, attained age, and exposure status

\begin{tabular}{|c|c|c|c|c|c|c|}
\hline \multirow[b]{2}{*}{ Gender } & \multirow[b]{2}{*}{ Age as of 1997} & \multicolumn{2}{|c|}{ Exposed* } & \multicolumn{2}{|c|}{ Nonexposed } & \multirow{2}{*}{$\begin{array}{c}\begin{array}{c}\text { General population } \\
\text { survey }\end{array} \\
\text { Average }(\mathrm{SE}) \\
\text { height }(\mathrm{cm})\end{array}$} \\
\hline & & No.\# & $\begin{array}{l}\text { Average (SE) } \\
\text { height }(\mathrm{cm})\end{array}$ & No.\# & $\begin{array}{l}\text { Average (SE) } \\
\text { height }(\mathrm{cm})\end{array}$ & \\
\hline \multirow[t]{3}{*}{ Male } & $<30$ & 278 & $182.1(0.5)$ & 265 & $181.9(0.5)$ & $183.5(0.2)$ \\
\hline & $30-39$ & 520 & $181.8(0.3)$ & 497 & $181.8(0.3)$ & $182.2(0.2)$ \\
\hline & $40-49$ & 496 & $180.5(0.3)$ & 366 & $180.2(0.4)$ & $180.4(0.2)$ \\
\hline \multirow[t]{5}{*}{ Female } & $<30$ & 211 & $169.4(0.4)$ & 217 & $169.4(0.4)$ & $169.6(0.2)$ \\
\hline & $30-39$ & 416 & $168.0(0.3)$ & 388 & $168.1(0.3)$ & $168.7(0.1)$ \\
\hline & $40-49$ & 420 & $166.8(0.3)$ & 311 & $166.8(0.3)$ & $167.3(0.1)$ \\
\hline & $\geq 50$ & 120 & $167.3(0.5)$ & 125 & $166.6(0.6)$ & $166.2(0.2)$ \\
\hline & All & 1167 & $167.7(0.2)$ & 1041 & $167.8(0.2)$ & \\
\hline
\end{tabular}

* $p$ Value $(t$ test exposed $v s$ unexposed $)>0.2$ for all comparisons.

\# Missing observation for adult height: exposed males (15), nonexposed males (20), exposed females (11), nonexposed females (14); excludes 3 nonexposed subjects $60-69$ y of age.

$\dagger$ Self-reported height based on periodic population survey among 22344 Dutch citizens by Statistics Netherlands (Ref. 27).

The distribution of females over three categories of menarcheal age was similar among exposed and nonexposed subjects, with roughly $70 \%$ reporting ages of $12-14 \mathrm{y}$ and $15 \%$ each in the categories of less than $12 \mathrm{y}$ and older than $14 \mathrm{y}$ at menarche, respectively (Table 6). In the subgroup of women younger than 20 y at first treatment, only $16 \%$ had reached menopause as of September 1997, and menopausal status was unknown in another 16\% (Table 6). Exposed postmenopausal females were more likely $\left[\mathrm{p}\left(\chi^{2}\right)=0.0001\right]$ than nonexposed females to have had a surgical menopause $(32 \%$ and $16 \%$, respectively). To address timing of menopause, we used the subset of 284 women who were treated by the ENT physician before age 20, who were older than 45 y of age in 1997, and who were postmenopausal at time of questionnaire completion. Of the 134 exposed and 150 nonexposed women, $29 \%$ and $30 \%$, respectively, had reached menopause before age 45 , and the average ages at menopause were 46.3 and $46.9 \mathrm{y}$, respectively.

With regard to reproductive characteristics, exposed females were slightly more likely to have had children $(\mathrm{OR}=1.1)$ and to report a history of fertility problems $(\mathrm{OR}=1.2)$ or miscarriages $(\mathrm{OR}=1.1)$, compared with nonexposed females, although the differences were very small and statistically nonsignificant (Table 6). The number of reported miscarriages was similarly distributed over exposure groups (Table 6). Among males treated before the age of 10 , the OR for having children 
was 0.9 (95\% CI: $0.7-1.0)$ and more exposed than nonexposed men reported a history of fertility problems $(\mathrm{OR}=1.4,95 \%$ CI: 1.0-2.1) (Table 6). Analyses for a history of fertility problems were then repeated by dose to the pituitary gland. Overall, there was a statistically significant trend of increasing risk with increasing pituitary dose $(p=0.004)$ in males, which remained apparent when the nonexposed group was excluded $(p=0.02)$. Compared with the nonexposed group, the OR for fertility problems by tertiles of pituitary dose were $1.3,1.1$, and 1.8. Among females, there was no dose trend for fertility problems $(p>0.5)$, with OR of 1.0, 1.3, and 1.0 by tertiles of pituitary dose.

\section{DISCUSSION}

We assessed long-term risk of noncancer disorders and NMSC in the head and neck area after low-dose radiation exposures from NRI in The Netherlands. Main outcomes included benign tumors in the head and neck area, BCC, SCC, thyroid disorders, and conditions related to regulatory control

Table 6. Reproductive characteristics and attained age by sex among participants of The Netherlands NRI cohort study survey, restricted to those treated before age $10 y$

\begin{tabular}{|c|c|c|c|c|c|c|c|c|c|c|}
\hline \multirow[b]{3}{*}{ Characteristic* } & \multicolumn{5}{|c|}{ Females } & \multicolumn{5}{|c|}{ Males } \\
\hline & \multicolumn{2}{|c|}{$\begin{array}{c}\text { Exposed } \\
(n=1178)\end{array}$} & \multicolumn{2}{|c|}{$\begin{array}{l}\text { Nonexposed } \\
(n=1057) \$\end{array}$} & \multirow{2}{*}{$\begin{array}{c}\text { OR } \\
(95 \% \mathrm{CI}) \$\end{array}$} & \multicolumn{2}{|c|}{$\begin{array}{c}\text { Exposed } \\
(n=1440)\end{array}$} & \multicolumn{2}{|c|}{$\begin{array}{l}\text { Nonexposed } \\
(n=1269)\end{array}$} & \multirow{2}{*}{$\begin{array}{c}\text { OR } \\
(95 \% \mathrm{CI}) \$\end{array}$} \\
\hline & No. & $(\%)$ & No. & $(\%)$ & & No. & $(\%)$ & No. & $(\%)$ & \\
\hline \multicolumn{11}{|l|}{ Attained age (y) } \\
\hline$<30$ & 215 & $(18.3)$ & 220 & $(20.8)$ & & 282 & (19.6) & 270 & $(21.3)$ & \\
\hline $30-39$ & 418 & $(35.5)$ & 391 & $(37.0)$ & & 524 & $(36.4)$ & 502 & $(39.6)$ & \\
\hline $40-49$ & 424 & $(36.0)$ & 319 & $(30.2)$ & & 501 & $(34.8)$ & 372 & $(29.3)$ & \\
\hline$\geq 50$ & 121 & $(10.3)$ & 127 & $(12.0)$ & & 133 & $(9.2)$ & 125 & $(9.8)$ & \\
\hline & \multicolumn{4}{|c|}{$p=0.02 \dagger$} & \multicolumn{6}{|c|}{$p=0.03$} \\
\hline \multicolumn{11}{|l|}{ Age at menarche (y) } \\
\hline$<12$ & 169 & (14.6) & 153 & $(14.7)$ & $1.0(0.8,1.3)^{* *}$ & & & & & \\
\hline $12-14$ & 823 & (70.9) & 716 & $(68.7)$ & & & & & & \\
\hline$>14$ & 168 & (14.5) & 173 & (16.6) & $0.8(0.7,1.1) \dagger \dagger$ & & & & & \\
\hline \multicolumn{11}{|c|}{$p=0.37$} \\
\hline \multicolumn{11}{|l|}{ Menopausal status\# } \\
\hline Premenopausal & 1003 & $(67.8)$ & 894 & $(68.5)$ & $1.0(0.8,1.3) t+$ & & & & & \\
\hline Postmenopausal & 236 & (15.9) & 201 & (15.4) & & & & & & \\
\hline Unknown & 241 & $(16.3)$ & 211 & $(16.2)$ & & & & & & \\
\hline \multicolumn{11}{|c|}{$p=0.90$} \\
\hline \multicolumn{11}{|l|}{ Number of miscarriages } \\
\hline 0 & 934 & $(81.0)$ & 865 & $(82.7)$ & $1.1(0.9,1.4) \$ \$$ & & & & & \\
\hline 1 & 167 & $(14.5)$ & 130 & (12.4) & & & & & & \\
\hline 2 & 33 & $(2.9)$ & 34 & $(3.3)$ & & & & & & \\
\hline$>2$ & 19 & (1.6) & 17 & (1.6) & & & & & & \\
\hline \multicolumn{11}{|c|}{$p=0.54$} \\
\hline \multicolumn{11}{|l|}{ Number of children } \\
\hline 0 & 399 & $(34.0)$ & 390 & $(37.1)$ & $1.1(0.9,1.4) \$ \$$ & 689 & $(48.2)$ & 587 & $(46.6)$ & $0.9(0.7,1.0) \$ \$$ \\
\hline $1-2$ & 611 & $(52.1)$ & 537 & $(51.1)$ & & 568 & $(39.8)$ & 526 & $(41.8)$ & \\
\hline $3-4$ & 160 & $(13.6)$ & 118 & $(11.2)$ & & 163 & $(11.4)$ & 137 & $(10.9)$ & \\
\hline \multirow[t]{2}{*}{$>4$} & 3 & $(0.3)$ & 6 & $(0.6)$ & & 8 & $(0.6)$ & 9 & $(0.8)$ & \\
\hline & \multicolumn{4}{|c|}{$p=0.13$} & \multicolumn{6}{|c|}{$p=0.53$} \\
\hline \multicolumn{11}{|l|}{ History of fertility problems } \\
\hline Never & 1053 & $(90.8)$ & 952 & $(92.3)$ & $1.2(0.9,1.6) \$ \$$ & 1341 & $(95.0)$ & 1202 & $(96.7)$ & $1.4(1.0,2.1) \$ \$$ \\
\hline Ovarian tube dysfunction & 21 & $(1.8)$ & 17 & (1.6) & & & & & & \\
\hline $\begin{array}{l}\text { Any type of sperm } \\
\text { deficiency }\end{array}$ & & & & & & 48 & (3.4) & 28 & (2.3) & \\
\hline Hormonal disorder & 33 & $(2.8)$ & 22 & $(2.1)$ & & 2 & $(0.1)$ & 2 & $(0.1)$ & \\
\hline Other cause & 30 & $(2.6)$ & 17 & (1.6) & & 16 & $(1.1)$ & 9 & $(0.7)$ & \\
\hline \multirow[t]{2}{*}{ Unknown cause } & 23 & $(2.0)$ & 23 & $(2.2)$ & & 4 & $(0.3)$ & 3 & $(0.2)$ & \\
\hline & & & & & & & & .32 & & \\
\hline
\end{tabular}

* Due to missing observations, numbers do not always add up to total.

$\dagger p$ Value of crude $\chi^{2}$ test to assess evidence of heterogeneity by exposure status for the distribution of each of the listed characteristics.

$\$$ Mean attained age 38.6 y among exposed and 38.3 y among nonexposed females; 38.3 among exposed and 37.7 among nonexposed males.

$\$$ OR for exposed compared with nonexposed group, adjusted for attained age $(<30,30-39,40-49$, and $50+y)$.

\# Analysis based on females first treated before age 20 (1480 exposed and 1306 nonexposed females).

$* *<12$ vs older.

$\dagger \dagger>14$ vs younger.

t† Postmenopausal vs premenopausal.

\$ Ever vs never. 
of anterior pituitary hormones, such as growth and reproductive characteristics. No strongly elevated risks were demonstrated for any of the conditions we studied. The highest risk estimates were observed for head and neck $\mathrm{BCC}$ of the skin $(\mathrm{OR}=2.6)$, thyroid nodular disease $(\mathrm{OR}=1.4)$, and male fertility problems $(\mathrm{OR}=1.4)$.

In contrast to findings reported after childhood head and neck x-ray treatments for thymic enlargement (11), tinea capitis (10), and enlarged tonsils (9) we did not observe an elevated risk of salivary gland tumors among NRI-exposed subjects. In the study by Schneider et al. (9), a strong dose-response relationship was demonstrated at a dose range of 0.01-15.8 Gy (mean, 4.2 Gy; excess relative risk per gray $=19.6$; 95\% CI: $0.16-\infty)$. In our study, average dose to the parotid gland was only 0.07 Gy (maximum, $0.28 \mathrm{~Gy}$ ).

We further demonstrated a 2.6-fold borderline significant risk of (medically confirmed) BCC of the head and neck area. The average dose to the facial skin was $3.2 \mathrm{cGy}$. Long-term excess risk of $\mathrm{BCC}$ has been reported in several populations with skin doses of several grays from external radiation (2932). The relative risk of NMSC is thought to be inversely associated with age at exposure (33). In the New York tinea capitis cohort, Shore et al. (29) reported particularly increased risk of skin cancer among irradiated white subjects with light complexions, which led to the hypothesis of UV radiation as a cofactor for radiogenic NMSC. Their finding was not confirmed in studies among atomic bomb survivors, although BCC was the major type of skin cancer associated with radiation dose in that population (31).

With NRI, appreciable skin radiation doses were only received by the facial skin, which is also commonly exposed to UV radiation. However, in our cohort, average dose to the facial skin was more than 10-fold lower compared with the tinea capitis studies $(29,30)$. It is tempting to speculate on NRI-induced BCC because we found some suggestion of elevated risk of head and neck BCC, mainly in subjects whose skin was exposed to the highest radiation dose. Also, $84 \%$ of all $\mathrm{BCC}$ among exposed subjects were found in the head and neck area, versus $43 \%$ of BCC in nonexposed subjects. However, a report from the Eindhoven Cancer Registry (19751988 ) showed that $81-84 \%$ of all BCC occurred in the head and neck area (34). Similar proportions were reported by Holme et al. (35) for repeated surveys conducted in SouthWales, i.e. 81\% (1988 survey) and 75\% (1998 survey). The agreement of the proportion of head and neck BCC in the exposed group with the population-based data renders an association with NRI less likely. Moreover, the observation may imply a deviant pattern among the nonexposed, which has pushed the OR for BCC of the head neck area upward. Bias or chance might explain this finding (see below). Only two SCC were observed among exposed subjects. Both SCC were tumors of the lower lip, which are known to be associated with sun exposure and smoking (36). The affected individuals were both heavy smokers with 35 and 56 y of smoking.

Chronic neuroendocrine sequelae such as disturbances of $\mathrm{GH}$ and gonadotropin ( $\mathrm{LH}$ and $\mathrm{FSH}$ ) regulatory processes are well known among cancer patients and patients with pituitary disease, who received high-dose radiation therapy involving the pituitary-hypothalamic axis (cranial doses $>18$ Gy) (19, $20,37)$. Studies among childhood cancer survivors have demonstrated a higher susceptibility to radiation-induced growth disorders among those treated at the youngest ages $(19,21)$. However, in agreement with two other studies $(23,38)$, we found no evidence of reduced adult height among subjects treated with NRI in childhood.

Self-reported height in the NRI cohort also showed good agreement with Dutch population-based self-reported data (27), although males younger than $30 \mathrm{y}$ of age in 1997 tended to be slightly less tall than the reference population. However, the subgroup in the NRI cohort consisted mainly of males aged 25-29 y whereas the reference data covered the full range of 20 - to 29-y-olds. Given the strong and well-described secular trend of increasing height in more recent birth cohorts (39) (clearly demonstrated in our data), the slightly decreased height for this particular age group in our cohort is likely to be caused by a difference in the age distribution.

Among NRI-exposed females, no increased risks were seen for early menarche, early menopause, or fertility problems, reproductive characteristics that can be affected in women who were treated with high-dose cranial radiation, especially at young ages $(19,40)$. Yeh and others $(18,22)$ recently reported on prolonged follow-up ( $>40 \mathrm{y}$ ) of a Maryland cohort of subjects exposed to NRI during childhood, but at higher doses compared with our study. They also found few differences between exposed and nonexposed women with regard to reproductive characteristics, although exposed women were slightly less likely to be still menstruating in 1995 , were older at menopause, but, were in general also older than nonexposed women (18). Our evaluation of menopause is too early for definitive conclusions, as only $12 \%$ of the women who were first treated before reaching 20 y of age had reached age 50 at end of follow-up. The comparable proportion of postmenopausal women, but higher probability of a surgical menopause among NRI-exposed subjects, was surprising. It might be a chance finding, but the issue warrants further examination in future follow-up studies of this cohort.

Among males but not females treated with NRI, a slightly elevated risk of fertility problems compared with the nonexposed group $(\mathrm{OR}=1.4)$ and a positive dose-response trend were observed. In a study among childhood cancer survivors, male fertility was more affected than female fertility; however, analyses by treatment showed that the difference by sex was restricted to children treated with chemotherapy, and not apparent among patients treated with radiotherapy above the abdomen (41). Also, no elevated risk of fertility problems has been demonstrated in the Maryland cohort (22), at considerably higher pituitary doses compared with our study. Therefore, it is questionable if the observed association with male fertility problems represents a true effect. Because half of the cohort is still younger than $40 \mathrm{y}$, prolonged follow-up, including medical verification, will be useful to address this question in more detail.

The regulation of thyroid stimulating hormone (TSH) levels is usually less sensitive to radiation damage at the hypothalamic-pituitary level compared with both GH and gonadotropin regulation, except for very high dose exposures (37). Never- 
theless, thyroid disorders are of potential interest, as the thyroid gland itself was exposed to radiation and is known to be extremely radiosensitive at young ages (42). Elevated risk of thyroid adenoma after childhood head and neck radiation has been demonstrated at thyroid doses below 0.2 Gy $(12,43)$. We did not find a clearly elevated risk for thyroid nodules among NRI-exposed subjects, although more cases were observed among exposed compared with nonexposed females. Of all exposed subjects, only $4 \%$ received thyroid doses exceeding 4 cGy, and none of these subjects developed thyroid nodular disease. Elevated risks of other thyroid disorders, such as hypothyroidism and Graves disease, have been reported after high-dose thyroid and/or pituitary radiation exposures among patients receiving cancer treatment $(20-60 \mathrm{~Gy})(13,14,44)$. The lack of association with NRI is not surprising in this respect.

The advantages and limitations of our study design should be taken into account when interpreting our results. The Netherlands NRI cohort is the largest that has been studied to date. Cohort identification was based on individual medical treatment records from participating ENT clinics; therefore, misclassification of exposure status is highly unlikely. The cohort was followed for 18 to more than $50 \mathrm{y}$, with $92 \%$ of all subjects traced (similar for exposed and nonexposed subjects).

Selection bias is a potential problem, as a result of differences between exposed and nonexposed subjects in questionnaire participation. Nonresponse rates were $13 \%$ among exposed and $16 \%$ among nonexposed subjects. However, for the cancer outcomes, a cancer registry linkage procedure (19891996) indicated that similar numbers of cancer cases were missed among exposed and nonexposed nonresponding subjects (23). A validation study for the cancer incidence analyses (Ronckers et al., unpublished manuscript) further revealed that failure to obtain consent for medical verification was a major determinant of case ascertainment success rate for both exposed and nonexposed subjects. Although the lack of selective processes with regard to cancer outcomes does not necessarily reflect selection relating to noncancer outcomes, we would expect any selective effect to be stronger for cancer outcomes. Refusal to participate in the questionnaire survey was also slightly more common among nonexposed (16\%) than exposed $(13 \%)$ subjects; unfortunately, no data on disease status are available for subjects who refused to participate.

Misclassification of disease outcomes is also a potential problem, as we had to rely on self-report in the questionnaires. However, for benign tumors, nonmelanoma skin tumors, and thyroid disorders, only medically confirmed diagnoses were included in the analysis. Consent for medical confirmation and availability of medical records limited the medically confirmed cases of thyroid disorders available for analysis to approximately $50 \%$ of all self-reported cases for both exposed and nonexposed subjects. Among all subjects who reported a history of skin lesions, and were asked for their consent to contact the treating physician, medical verification was permitted by $84 \%$ of exposed and $77 \%$ of nonexposed subjects.

We tried to avoid bias by blinding research assistants responsible for coding of disease outcome for exposure status and by not mentioning exposure status in the letters to the treating physicians. We found no evidence of selective physician cooperation, as $85 \%$ and $90 \%$ of all requests with regard to verification of thyroid diseases for exposed and nonexposed subjects were returned. For skin tumors, the physician cooperation proportion was over $95 \%$ in both groups.

Surveillance bias is relevant for our study in that NRIexposed subjects might more often have sought medical screening for thyroid disorders. However, only $15 \%$ of all NRI-exposed participants mentioned NRI in a questionnaire item on radiation treatments. Moreover, there were no significant differences between exposed subjects who mentioned NRI in the questionnaire and those who did not, with regard to several self-reported disease outcomes.

Although we did not demonstrate abnormal disease patterns that might result from hormone-regulated processes, we cannot exclude the possibility that low-dose radiation to the pituitary gland causes hormone imbalances without clinically overt symptoms. As this study did not involve clinical examinations or blood sampling, no data on hormone levels are available to further evaluate this possibility.

With regard to the analysis, we note that some positive findings may be due to chance. We used age-adjusted OR to estimate underlying risk ratios (RR), although the OR will overestimate the RR if an outcome has a more than $10 \%$ frequency among nonexposed subjects $(45,46)$. As this limit is exceeded for all reproductive characteristics, the OR for these variables are likely to slightly overestimate the underlying RR.

In summary, we found no evidence of greatly elevated risk of benign head and neck tumors or thyroid disorders after childhood NRI in The Netherlands. Our observation of an increased risk of facial BCC among NRI-exposed subjects is interesting, and this possible association should be explored further in future studies of NRI-exposed populations. There was no clear evidence of radiation-related pituitary gland dysfunction. However, definite conclusions regarding timing of menopause and male fertility require further prolonged follow-up of our cohort because of the young age of the cohort at present.

Acknowledgments. We thank the following ENT physicians and their staff for their cooperation: E.R. Havermans, P.S. Mulkens, G.M. van de Meerakker, T.J. Bierman, A.A. Annyas, E.R. Rijntjes, P.H.M.T. Olde Kalter, H.J. ter Stege, and G.H. Bovenhorst. We also thank Diane Fuchs (Westat Inc.) for administrative assistance.

\section{REFERENCES}

1. Crowe SJ, Baylor JW 1939 The prevention of deafness. JAMA 112:585-590

2. Bordley JE, Hardy WG 1955 The efficacy of nasopharyngeal irradiation for the prevention of deafness in children. Acta Otolaryngol Suppl 120:1-49

3. Anonymous 1955 Radium treatment of deafness in children [editorial]. BMJ 11:426

4. van Dishoeck HAE 1950 Bestraling van de nasopharynx met radium. Ned Tijdschr Geneeskd 94:224-227

5. Hendricks JE 1945 The use of radium in the aerotitis control program of the army air forces. Ann Otol Rhinol Laryngol 54:722-724

6. Warlick SR 1996 Military use of nasopharyngeal irradiation with radium during World War II. Otolaryngol Head Neck Surg 115:391-394

7. Mellinger-Birdsong AK 1996 Estimated numbers of civilians treated with nasopharygeal radium irradiation in the United States. Otolaryngol Head Neck Surg 115:429432 
8. Verduijn PG 1988 Late health effects of radiation for eustachian tube dysfunction; a non-concurrent prospective study. PhD thesis, Erasmus Universiteit, Rotterdam, The Netherlands, pp 33-114

9. Schneider AB, Lubin J, Ron E, Abrahams C, Stovall M, Goel A, Shore-Freedman E, Gierlowski TC 1998 Salivary gland tumors after childhood radiation treatment fo benign conditions of the head and neck: dose-response relationships. Radiat Res 149:625-630

10. Modan B, Chetrit A, Alfandary E, Tamir A, Lusky A, Wolf M, Shpilberg O 1998 Increased risk of salivary gland tumors after low-dose radiation. Laryngoscope 108:1095-1097

11. Hildreth NG, Shore RE, Hempelmann LHG, Rosenstein M 1985 Risk of extrathyroid tumors following radiation treatment in infancy for thymic enlargement. Radiat Res 102:378-391

12. Shore RE, Hildreth N, Dvoretsky P, Andresen E, Moseson M, Pasternack B 1993 Benign thyroid adenomas among persons $\mathrm{X}$-irradiated in infancy for enlarged thymus glands. Radiat Res 134:217-223

13. DeGroot LJ 1993 Effects of irradiation on the thyroid gland. Endocrinol Metab Clin North Am 22:607-615

14. Hancock SL, McDougall IR, Constine LS 1995 Thyroid abnormalities after therapeutic external radiation. Int J Radiat Oncol Biol Phys 31:1165-1170

15. Ronckers CM, Land CE, Verduijn PG, Hayes RB, Stovall M, van Leeuwen FE 2001 Cancer mortality after nasopharyngeal radium irradiation in The Netherlands: a cohort study. J Natl Cancer Inst 93:1021-1027

16. Stovall M 1996 Nasopharyngeal brachytherapy for lymphoid hyperplasia: review of dosimetry. Otolaryngol Head Neck Surg 115:395-398

17. Sandler DP, Comstock GW, Matanoski GM 1982 Neoplasms following childhood radium irradiation of the nasopharynx. J Natl Cancer Inst 68:3-8

18. Yeh HC, Matanoski GM, Wang NY, Sandler DP, Comstock GW 2001 Cance incidence following childhood nasopharyngeal radium irradiation: a follow-up study in Washington County, Maryland. Am J Epidemiol 153:749-756

19. Noorda EM, Somers R, van Leeuwen FE, Vulsma T, Behrendt H; The Dutch Late Effects Study Group 2001 Adult height and age at menarche in childhood cancer survivors. Eur J Cancer 37:605-612

20. Sklar CA, Constine LS 1995 Chronic neuroendocrinological sequelae of radiation therapy. Int J Radiat Oncol Biol Phys 1:1113-1121

21. Littley MD, Shalet SM, Beardwell CG, Robinson EL, Sutton ML 1989 Radiationinduced hypopituitarism is dose dependent. Clin Endocrinol 31:363-373

22. Yeh HC 1997 Health effects after childhood nasopharyngeal radium irradiation. $\mathrm{PhD}$ thesis, School of Hygiene and Public Health, The Johns Hopkins University, Baltimore, MD, pp 117-239

23. Ronckers CM, van Leeuwen FE, Hayes RB, Verduijn PG, Stovall M, Land CE 2002 Cancer incidence after naspharyngeal radium irradiation. Epidemiology 13:552-560

24. Verduijn PG, Hayes RB, Habbema JDF, Looman C, van der Maas PJ 1989 Mortality after nasopharyngeal radium irradiation for eustachian tube dysfunction. Ann Otol Rhinol Laryngol 98:839-844

25. Rothman KJ, Greenland S 1998 Modern Epidemiology, 2nd ed. Lippincott-Raven, Philadelphia

26. Kleinbaum DG, Kupper LL, Muller KE, Nizam A 1998 Applied Regression Analysis and Other Multivariable Methods, 3rd Ed. Duxbury Press, Pacific Grove, CA
27. StatLine Central Bureau voor de Statistiek. POLS 2001 1997/1999 survey. Available at http://statline.cbs.nl/statweb. Accessed May 19, 2001

28. World Health Organization 1975 Manual of the International Statistical Classification of Diseases, Injuries and Causes of Death (ICD-9). World Health Organization, Geneva, Switzerland

29. Shore RE, Moseson M, Xue X, Tse Y, Harley N, Pasternack BS 2002 Skin cancer after X-ray treatment for scalp irradiation. Radiat Res 157:410-418

30. Ron E, Modan B, Preston D, Alfandary E, Stovall M, Boice Jr JD 1991 Radiationinduced skin carcinomas of the head and neck. Radiat Res 125:318-325

31. Ron E, Preston DL, Kishikawa M, Kobuke T, Iseki M, Tokuoka S, Tokunaga M, Mabuchi K 1998 Skin tumor risk among atomic-bomb survivors in Japan. Cancer Causes Control 9:393-401

32. van Vloten WA, Hermans J, van Daal WAJ 1987 Radiation-induced skin cancer and radiodermatitis of the head and neck Cancer 59:411-414

33. International Commission on Radiological Protection (ICRP) 1991 The Biologica Basis for Dose Limitation in the Skin. ICRP Publication 59. Pergamon Press, Oxford

34. Coebergh JW, Neumann HA, Vrints LW, van der Heijden L, Meijer WJ, VerhagenTeulings MT 1991 Trends in the incidence of non-melanoma skin cancer in the SE Netherlands 1975-1988: a registry-based study. Br J Dermatol 125:353-359

35. Holme SA, Malinovszky K, Roberts DL 2000 Changing trends in non-melanoma skin cancer in South Wales, 1988-98. Br J Dermatol 143:1224-1229

36. Doll R 1996 Cancers weakly related to smoking. Br Med Bull 52:35-49

37. Littley MD, Shalet SM, Beardwell CG 1990 Radiation and hypothalamic-pituitary function. Baillieres Clin Endcrinol Metabol 4:147-152

38. Hazen RW, Pifer JW, Toyooka ET, Livingood J, Hempelmann LH 1966 Neoplasms following irradiation of the head. Cancer Res 26-I:305-311

39. Fredriks AM, van Buuren S, Burgmeijer RJ, Meulmeester JF, Beuker RJ, Brugman E, Roede MJ, Verloove-Vanhorick SP, Wit JM 2000 Continuing positive secular growth change in The Netherlands 1955-1997. Pediatr Res 47:316-323

40. Byrne J 1999 Infertility and premature menopause in childhood cancer survivors. Med Pediatr Oncol 33:24-28

41. Byrne J, Mulvihill JJ, Myers MH, Connelly RR, Naughton MD, Krauss MR, Steinhorn SC, Hassinger DD, Austin DF, Bragg K, et al. 1987 Effects of treatment on fertility in long-term survivors of childhood or adolescent cancer. N Engl J Med 317:1315-1321

42. Ron E, Lubin JH, Shore RE, Mabuchi K, Modan B, Pottern LM, Schneider AB, Tucker MA, Boice Jr JD 1995 Thyroid cancer after exposure to external radiation: a pooled analysis of seven studies. Radiat Res 141:259-277

43. Pottern LM, Kaplan MM, Larsen PR, Silva JE, Koenig RJ, Lubin JH, Stovall M, Boice Jr JD 1990 Thyroid nodularity after childhood irradiation for lymphoid hyperplasia: a comparison of questionnaire and clinical findings. J Clin Epidemiol 43:449-460

44. Hancock SL, Cox RS, McDougall R 1991 Thyroid disease after treatment of Hodgkin's disease. N Engl J Med 325:599-605

45. Zhang J, Yu KF 1998 What's the relative risk? A method of correcting the odds ratio in cohort studies of common outcomes. JAMA 280:1690-1691

46. McNutt LA, Hafner JP, Xue X 1999 Correcting the odds ratio in cohort studies of common outcomes. [letter] JAMA 282:529 